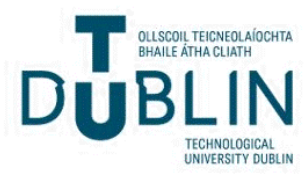

Technological University Dublin

ARROW@TU Dublin

Articles

Crest: Centre for Research in Engineering

Surface Technology

2014-06-30

\section{Developments of Cobalt Ferrite Nanoparticles Prepared by The Sol-Gel Process}

\author{
M. Sajjiaa \\ Dublin City University \\ Mohamed Oubaha \\ Technological University Dublin, mohamed.oubaha@tudublin.ie \\ M. Hasanuzzaman \\ Dublin City University
}

See next page for additional authors

Follow this and additional works at: https://arrow.tudublin.ie/cenresart

Part of the Physical Sciences and Mathematics Commons

\section{Recommended Citation}

Sajjiaa, M., Oubaha, M., Hasanuzzaman, M. and Olabi, A. G. (2014) Developments of Cobalt Ferrite Nanoparticles Prepared by The Sol-Gel Process. Ceramics International, Volume 40, Issue 1, Part A, January 2014, Pages 1147-1154. doi:10.1016/j.ceramint.2013.06.116

This Article is brought to you for free and open access by the Crest: Centre for Research in Engineering Surface Technology at ARROW@TU Dublin. It has been accepted for inclusion in Articles by an authorized administrator of ARROW@TU Dublin. For more information, please contact arrow.admin@tudublin.ie, aisling.coyne@tudublin.ie,gerard.connolly@tudublin.ie.

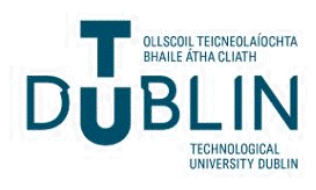


Authors

M. Sajjiaa, Mohamed Oubaha, M. Hasanuzzaman, and A.G. Olabi

This article is available at ARROW@TU Dublin: https://arrow.tudublin.ie/cenresart/52 


\title{
Developments of cobalt ferrite nanoparticles prepared by the sol-gel process
}

\author{
M. Sajjia ${ }^{\mathrm{a}}$, M. Oubaha ${ }^{\mathrm{b}}$, M. Hasanuzzaman ${ }^{\mathrm{a}}$, A.G. Olabi ${ }^{\mathrm{c}, *}$ \\ ${ }^{a}$ School of Mechanical and Manufacturing Engineering, Dublin City University, Glasnevin, Dublin 9, Ireland \\ ${ }^{\mathrm{b}}$ Optical Sensor Laboratory, National Centre for Sensor Research, Dublin City University, Glasnevin, Dublin 9, Ireland \\ ${ }^{\mathrm{c}}$ School of Engineering, University of the West of Scotland, Paisley, PA1 2BE, UK
}

Received 19 March 2013; received in revised form 13 June 2013; accepted 30 June 2013

Available online 4 July 2013

\begin{abstract}
In the phase of the study reported, the sol-gel technique was followed in the preparation of cobalt ferrite amorphous powder following the same procedure which was selected as the best approach as described in a previous study. It was assumed that there must be a correlation between the heat treatment operational parameters and the structural properties of the material being synthesized. Similarly, it was understood that some heat treatment is necessary to completely decompose the organic and nitrate contents present in the amorphous powder. Having ensured that the heat treatment parameters could be changed without producing a material with poorer properties, it was then possible to produce batches of powders using milder conditions in the heat treatment operation. The particle size distributions of these new batches of nanoparticles were estimated to be in the range 7-28 $\mathrm{nm}$ and since the results showed promise, their magnetic properties were also determined.

(c) 2013 Elsevier Ltd and Techna Group S.r.l. All rights reserved.
\end{abstract}

Keywords: A. Sol-gel; C. Magnetic properties; Cobalt ferrite nanoparticles; Heat treatment

\section{Introduction}

Cobalt ferrite nanoparticles have recently been of interest to many researchers due to their diverse potential industrial and biomedical applications [1-3]. Cobalt ferrite nanoparticles were proposed as a promising solution in biomedical applications, such as magnetic thermo-drug delivery and hyperthermia, biosensors and magnetic resonance imaging [4-6].

Many techniques have already been employed in the development of cobalt ferrite nanoparticles including a novel solvothermal approach [7], microemulsions [8], a new nonaqueous route [9], a chemical co-precipitation method [10] and the sol-gel technique [11].

Among the various liquid-phase chemical techniques, reported in the literature and employed for the synthesis of cobalt ferrite nanoparticles, the sol-gel process (including a heat treatment operation) is probably the most effective and feasible route to develop high purity, homogeneous and crystalline nanoparticles. The sol-gel technique is a low temperature process which

\footnotetext{
*Corresponding author. Tel.: +44 1418483450.

E-mail address: abdul.olabi@uws.ac.uk (A.G. Olabi).
}

involves hydrolysis and condensation reactions of metal precursors (salts or alkoxides) leading to the formation of a threedimensional inorganic network [12,13]. Metal hydroxyl groups $(\mathrm{M}-\mathrm{OH})$ are formed during the hydrolysis. These groups subsequently condense into strong, rigid and irreversible metal-oxometal bridges (M-O-M).

In a previous study [14], cobalt ferrite powders were prepared and developed. It was suspected that the nanoparticles which had been synthesized had agglomerated and formed larger particles as a result of the heat treatment operation. This is because these nanoparticles were found to be in the size range between 20 and $250 \mathrm{~nm}$. Therefore, there is a need to investigate whether the thermal energy released in the heat treatment operation could be reduced because it might be responsible for the undesired growth of particle size during this operation.

In the phase of the study reported in this paper, the sol-gel technique was followed in the preparation of cobalt ferrite amorphous powder following the same procedure which was selected as the best approach as described in the previous study. It was assumed that there must be a correlation between the heat treatment operational parameters and the structural properties (the 
crystallinity and the freedom from unwanted oxides) of the material being synthesized. Similarly, it was understood that some heat treatment is necessary to completely decompose the organic and nitrate contents present in the amorphous powder and finally to form the spinel structure without these kinds of impurities also. It was therefore important when attempting to change these operational parameters of the heat treatment that this would not result in a material with poorer properties. Having ensured that the heat treatment parameters could be changed without producing a material with poorer properties, it was then possible to produce batches of powders using milder conditions in the heat treatment operation. The particle size distributions of these new batches of nanoparticles were estimated and since the results showed promise, their magnetic properties were also determined.

\section{Experimental procedure}

\subsection{Material development}

The sol-gel synthesis was based on the formation of a stable and homogenous solution made by dissolving a mixture of Cobalt (II) nitrate hexahydrate $\left(\mathrm{Co}\left(\mathrm{NO}_{3}\right)_{2} \bullet 6 \mathrm{H}_{2} \mathrm{O}, \geq 99 \%\right.$, Fluka) and Iron (III) nitrate nonahydrate $\left(\mathrm{Fe}\left(\mathrm{NO}_{3}\right)_{3} \bullet 9 \mathrm{H}_{2} \mathrm{O}\right.$, $\geq 98 \%$, Sigma-Aldrich) in water, which is a hydrolysis reaction. The solution was transformed into a sol and then a gel by evaporation of the water, and during this time condensation reactions took place. Details of the whole preparation process are sketched in Fig. 1 [14].

The precursors were used as received without any further purification. In order to maintain the homogeneity in both the sol and the gel during the condensation and other reactions, avoiding any precipitation or sedimentation of the products of these reactions, citric acid (CA, Sigma-Aldrich) was employed

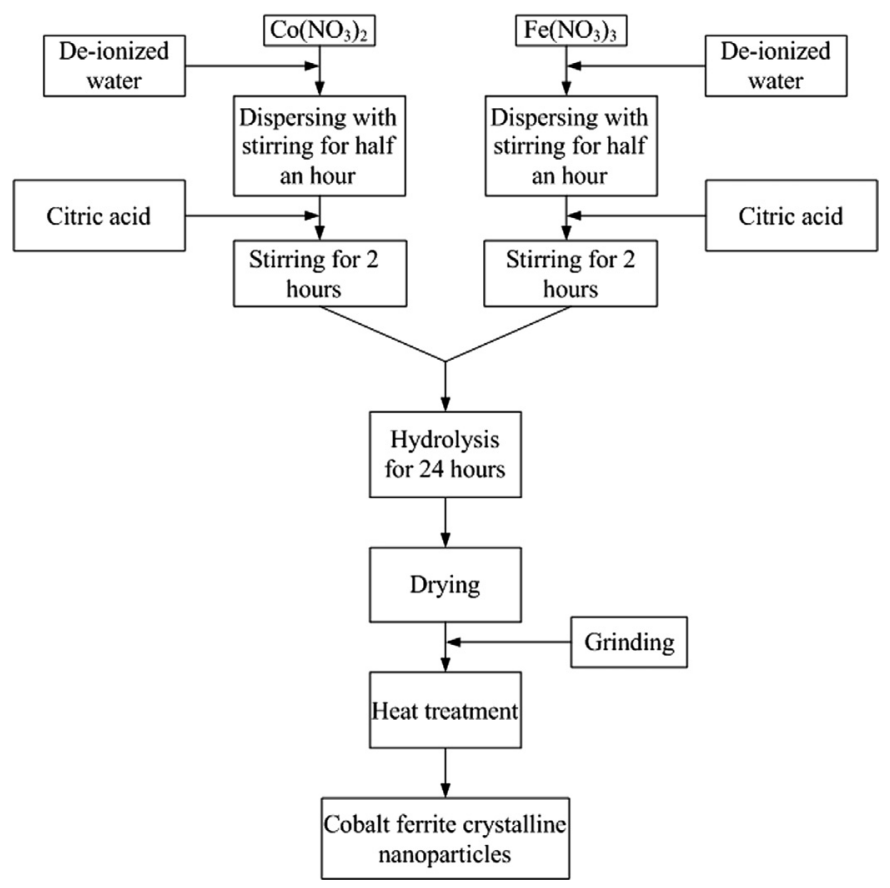

Fig. 1. Materials preparation [4]. as a chelating agent. Both precursors were initially separately dispersed in de-ionized water for half an hour by stirring. Following this dispersion, the chelating agent was added and the mixture was left reacting under vigorous stirring for $2 \mathrm{~h}$. Both solutions were then mixed together and left stirring for $24 \mathrm{~h}$ and after this the condensation reactions of both metal nitrates was allowed to take place. The quantity of each metal precursor was calculated so that the ratio of the two metals in the final material would be $\mathrm{Co}: \mathrm{Fe}=1: 2$ and the quantity of citric acid was estimated assuming that each ferric ion would require two molecules of citric acid and each cobaltous ion would require two molecules of the chelating agent as well, so that the metal ions would be adequately chelated.

\subsection{Methodology}

It is understood that most of the oxidation reactions which occur during the heat treatment operation take place above a temperature of $200{ }^{\circ} \mathrm{C}$. This follows as a result of the DTA/ TGA curves for the amorphous powder which are shown in Fig. 2. Therefore, in the initial investigation to determine whether the temperature used in the heat treatment operation could be reduced, the temperature range of $200-600{ }^{\circ} \mathrm{C}$ was selected for the initial trials and the $10 \mathrm{~h}$ dwelling time was maintained for each trial.

The methodology of this initial study consisted in a series of trials. In each trial the temperature of the heat treatment was different. The selected temperature was decreased for each member of the series from an initial value of $600{ }^{\circ} \mathrm{C}$ for the first trial in intervals of about $50{ }^{\circ} \mathrm{C}$ to a temperature of $200{ }^{\circ} \mathrm{C}$, being the lowest temperature of interest, while the dwell time was maintained at $10 \mathrm{~h}$. It was then planned that a second series of trials would be carried out in which this minimum temperature for the heat treatment would be maintained, while the dwell time would be progressively decreased from an initial value of $10 \mathrm{~h}$ in intervals of $2 \mathrm{~h}$, down to a final value of $2 \mathrm{~h}$.

Afterward, the material produced in each trial was analyzed by XRD, with the aim of identifying and then quantifying the impurities in the products. It was hoped that this work would identify a temperature for the heat treatment, below which

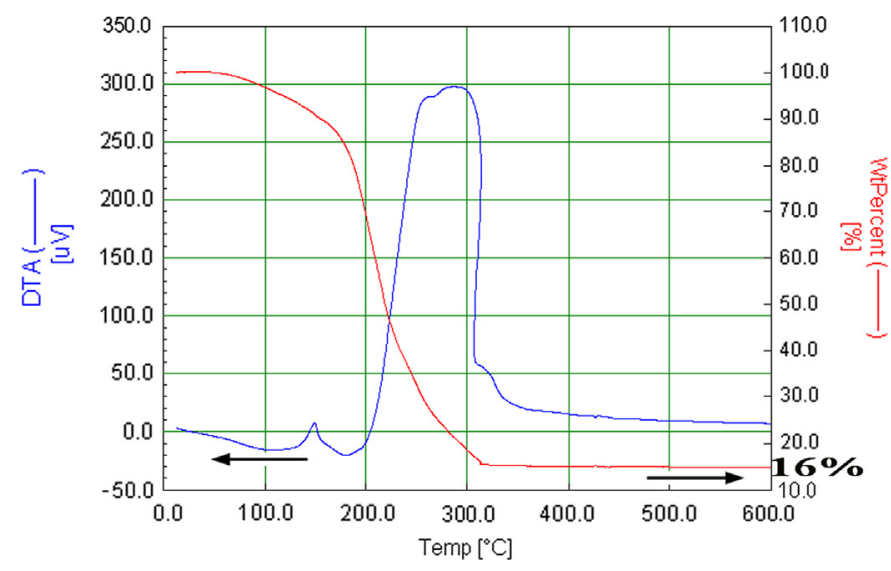

Fig. 2. DTA/TGA curves of cobalt ferrite amorphous powder. 
there would be problems with impurities, and above which the risk of impurities developing would be insignificant. This temperature would be the minimum temperature at which the heat treatment could be operated in a process to produce pure cobalt ferrite with its spinel structure.

However, as the work progressed it became clear that with a temperature of only $200{ }^{\circ} \mathrm{C}$, the heat treatment could still result in producing the cobalt ferrite with the spinel structure with no other oxides. At this point, the investigation became focussed on the dwell time of the heat treatment, and this was then studied. It could be safely assumed that investigations studying different dwell times (10, 8, 6, 4 and $2 \mathrm{~h})$ at temperatures which are much higher than the minimum temperature, e.g. 500 or $600{ }^{\circ} \mathrm{C}$, would result in products with the spinel structure and without impurities. As the research interest is to determine the critical conditions, it was believed it is better to focus the interest on studying the morphology and magnetic properties of nanoparticles prepared under these critical conditions whose significance lies in the fact that they are much more likely to be produced on a larger scale. The list of samples investigated in this study and their conditions of preparation are indicated in Table 1.

\subsection{Characterization}

A Horizontal Tube Furnace (Carbolite Ltd., Sheffield, UK) was used to carry out the heat treatment operation on the amorphous powders with $10{ }^{\circ} \mathrm{C} / \mathrm{min}$ as the heating/cooling ramp rates under ambient atmosphere. The structural characterization of powders was carried out by measuring their XRD patterns employing an X-ray diffractometer (D8 ADVANCEBRUKER) using $\mathrm{Cu}-\mathrm{K}_{\alpha}$ radiation. Differential Thermal Analysis (DTA) and Thermo-Gravimetric Analysis (TGA) were performed in air to determine the temperatures at which the decomposition and oxidation of the chelating agent take place. The curves were obtained using heating/cooling rates of $10{ }^{\circ} \mathrm{C} /$ min under ambient atmosphere to investigate and identify the purity of the materials. Fourier Transform Infrared Spectroscopy (FTIR) was used to investigate the molecular structure of the materials for comparison reasons. The morphology of

Table 1

Heat treatment conditions of prepared samples.

\begin{tabular}{lll}
\hline Sample & Heat treatment temperature $\left({ }^{\circ} \mathrm{C}\right)$ & Dwelling time $(\mathrm{h})$ \\
\hline $\mathrm{A}$ & 600 & 10 \\
$\mathrm{~B}$ & 500 & 10 \\
$\mathrm{C}$ & 450 & 10 \\
$\mathrm{D}$ & 400 & 10 \\
$\mathrm{E}$ & 350 & 10 \\
$\mathrm{~F}$ & 300 & 10 \\
$\mathrm{G}$ & 250 & 10 \\
$\mathrm{H}$ & 200 & 10 \\
$\mathrm{I}$ & 200 & 8 \\
$\mathrm{~J}$ & 200 & 6 \\
$\mathrm{~K}$ & 200 & 4 \\
$\mathrm{~L}$ & 200 & 2 \\
\hline
\end{tabular}

the materials (homogeneity and particle size) was observed by a Field Emission-Scanning Electron Microscope (FE-SEM). The magnetic properties (hysteresis loops) were recorded at both room temperature and $10{ }^{\circ} \mathrm{K}$ using a Vibrating Sample Magnetometer (VSM) with a maximum magnetic field of $50 \mathrm{kOe} .20 \mathrm{mg}$ of powder was used in each determination. The temperature dependence of the magnetization curve under zero-field cooled conditions was also recorded.

\section{Results and discussion}

\subsection{Structural and thermal analyses}

As reported in the literature [14,15], cobalt ferrite XRD pattern exhibits 8 peaks located between $2 \theta^{\circ}=15$ and $2 \theta^{\circ}=70$ as follows: $18.289,30.085,35.438,37.057,43.059$, $53.446,56.975,62.587$ corresponding to the related Miller indices which are: (111), (220), (311), (222), (400), (422), (511), (440), respectively. The respective intensities of these peaks against the intensity of the maximum peak located at $2 \theta^{\circ}=35.438$ are as follows: $10 \%, 30 \%, 100 \%, 8 \%, 20 \%, 10 \%$, $30 \%, 40 \%$.

The XRD patterns of the products prepared with the heat treatment operational parameters defined in Table 1 are presented in Fig. 3. One can observe that all the peaks related to cobalt ferrite spinel structure are identifiable in all the materials with no additional peaks and all patterns match with the JCPDS-ICDD file number of 22-1086.

Although each sample in the series was prepared at a different heat treatment temperature, in the range from $600{ }^{\circ} \mathrm{C}$ down to the minimum temperature of interest, i.e. $200{ }^{\circ} \mathrm{C}$, in each case the only phase observable in the XRD patterns is that of the cobalt ferrite spinel phase as indicated by the XRD patterns of samples A, B, C, D, E, F, G, and H. At that stage, it was thought that there would be no point in

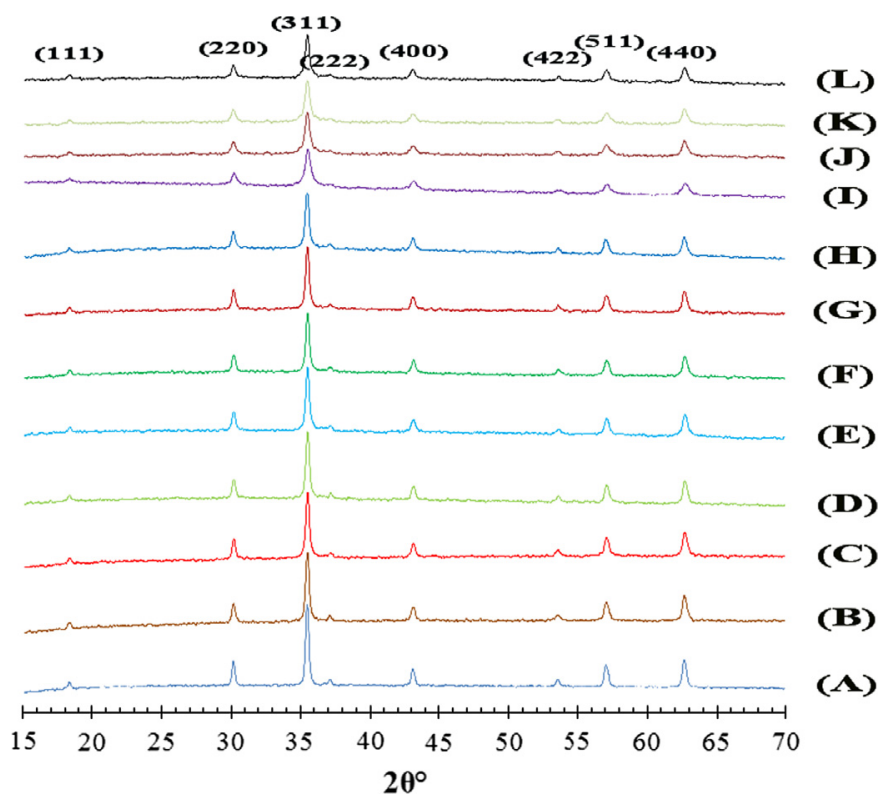

Fig. 3. XRD patterns of samples (A-L). 
operating the equipment with a dwell time of $10 \mathrm{~h}$ if reducing the time could also result in reducing the particle sizes. Therefore, in a further series of trials the $10 \mathrm{~h}$ dwell time was reduced to $8,6,4$, and then finally to $2 \mathrm{~h}$ while the temperature was maintained at $200{ }^{\circ} \mathrm{C}$. Again in each case the only phase observable in the XRD patterns is that of the spinel structure as indicated by the XRD patterns of samples I, J, K, and L shown in Fig. 3.

These results indicate the success of the particular form and arrangement of the sol-gel technique, described in the previous study in developing a material with the cobalt ferrite spinel structure. It can be assumed that with this particular choice of starting materials and procedures, the cobalt ferrite structure would have been obtained with a heat treatment temperature anywhere within the range between 200 and $600{ }^{\circ} \mathrm{C}$. However, as XRD patterns can only be used to identify crystalline structures present in a material they do not give any information about the purity of the materials, if these materials also contain substances which are not crystalline, such as organic constituents. It was therefore decided to perform thermal analyses such as DTA/TGA to identify the purity of the prepared materials taking into account non-crystalline substances. These other techniques would identify the minimum temperature and time required to complete the decomposition of the nitrates and the decomposition or oxidation of organic moieties, initially present in the precursors and in the chelating agent or having been produced in reactions during the sol-gel processing.

To pursue this approach further, the dwell times and temperatures of the heat treatment operation, which were designated above as $\mathrm{A}$ and $\mathrm{L}$ were selected for comparison, because they represent the two extremes of the parameters, being the strongest $600{ }^{\circ} \mathrm{C}$, for $10 \mathrm{~h}$ and the mildest $200{ }^{\circ} \mathrm{C}$, for $2 \mathrm{~h}$ respectively. The heat treatment operations were then carried out, but in the DTA/TGA equipment using the same starting material, the amorphous powder produced by the solgel process, and using the equipment's programmable ramp rates and set temperatures to repeat, as closely as possible, the operation of the horizontal tube furnace, normally used for the heat treatment operation. According to the work reported in the previous study, the heat treatment conditions designated as A were carried out already, in both the horizontal tube furnace, and in the DTA/TGA equipment (sample 14 and Fig. 7) [14]. The analyses suggest that the product, identified as cobalt ferrite with a spinel structure, at $350{ }^{\circ} \mathrm{C}$, became free of any organic or unstable inorganic impurities, because the solid (WtPercent[\%]) became stable with no further oxidation or decomposition reactions to form gases about and above $350{ }^{\circ} \mathrm{C}$. These results can therefore be used as a reference for comparison with the heat treatment parameters designated as $L$.

The thermal analysis following the heat treatment conditions designated by $\mathrm{A}$ is shown in Fig. 2. In the results one can observe that within the range of temperatures between room temperature and $600{ }^{\circ} \mathrm{C}$, the DTA curve exhibits two exothermic peaks or bands centered at $150{ }^{\circ} \mathrm{C}$ and $300{ }^{\circ} \mathrm{C}$. The band centered at $300{ }^{\circ} \mathrm{C}$ is actually spread out over a range of temperatures from $205{ }^{\circ} \mathrm{C}$ up to $345{ }^{\circ} \mathrm{C}$. This band seems to result from the superimposition of several overlapping bands. In fact, it is well known that the oxidation of various, similar organic compounds take place in this domain of temperatures. In this case, it is very likely that the width of the band results from both the decomposition of the nitrate ions, which were originally linked to both the $\mathrm{Co}$ and the $\mathrm{Fe}$ ions and the oxidation and decomposition of the citric acid, which have become linked to both the $\mathrm{Co}$ and the $\mathrm{Fe}$ ions. Furthermore, the TGA curve shows that the initial weight of material reduces to $16 \%$ of its original value during the heat treatment. The additional components contribute $84 \%$ to the total weight of the amorphous powder.

The results of the DTA/TGA following the heat treatment conditions designated by $L$ are shown in Fig. 4. It has already been shown using different equipment that the heat treatment conditions of $200{ }^{\circ} \mathrm{C}$ for $2 \mathrm{~h}$ produces cobalt ferrite with the correct spinel structure with no other oxides. However, one can observe in the TGA curve that the initial weight of the starting material reduces to only $29 \%$ of its original value. This is $13 \%$ higher than the final value when compared with the corresponding result for the heat treatment procedure designated by A. This must be attributed to the incomplete oxidation and decomposition of the organic and nitrate components. This result indicated the need to investigate the effects of the different parameters in the heat treatment operation more thoroughly and to identify the optimum set points which would produce the cobalt ferrite free of all additional components.

To identify the optimum heat treatment conditions, there were initially two alternative strategies which could be adopted: either (1) gradually to increase the dwell time while maintaining the heat treatment temperature at $200{ }^{\circ} \mathrm{C}$; or (2) gradually to increase the heat treatment temperature up towards $600{ }^{\circ} \mathrm{C}$, keeping the dwell time constant at $2 \mathrm{~h}$. However, it was considered most likely that increasing the heat treatment temperature would generally have a greater effect on the particle size, than an increase in the dwell time, and a growth in particle size is most undesirable in this study. Therefore, increasing the dwell time at a lower temperature

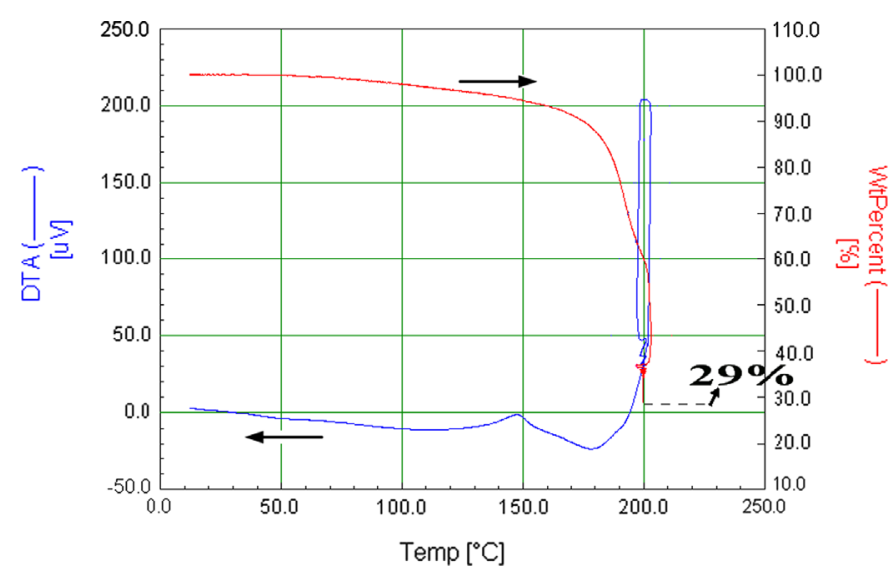

Fig. 4. DTA/TGA curves of sample (L). 
was considered to be a better strategy than increasing the temperature with a short dwell time.

This investigation started, therefore with $200{ }^{\circ} \mathrm{C}$ as the heat treatment temperature, and the dwell time was gradually increased in a series of trials using the DTA/TGA equipment. However, even when the dwell time had been extended to $10 \mathrm{~h}$, the TGA curve showed that the initial weight of the starting material was reduced only to $24 \%$ of the original value. This indicates that there was insufficient thermal energy to oxidize or decompose the organic and nitrate components completely.

A temperature of $250{ }^{\circ} \mathrm{C}$ was then selected and the same approach was repeated by gradually increasing the dwell time. Eventually, it was found that with the parameters of $250{ }^{\circ} \mathrm{C}$ and $10 \mathrm{~h}$ as the heat treatment temperature and time respectively, the desired result was achieved. The final point on the TGA curve at $250{ }^{\circ} \mathrm{C}$ was $16 \%$. These parameters had already been selected in earlier trials, and had been designated as $\mathrm{G}$. They represent the lowest thermal conditions for the heat treatment which will ensure the complete elimination of all impurities. The heat treatment operation with these settings would provide the smallest possible opportunity for the particle size to increase because the temperature would be kept to the minimum. The DTA/TGA curves for these heat treatment settings designated by $G$ are shown in Fig. 5. The final percentage point weight of the TGA curve is found to be equal to the equivalent final percentage point weight of the TGA curve following the heat treatment parameters designated by A (16\% of its initial weight). This demonstrates the complete elimination of all impurities and the attainment of cobalt ferrite as a single phase.

\subsection{FTIR analysis}

FTIR spectroscopic analyses were carried out on samples of the same amorphous powder, the product of the sol-gel processing described above, after they had been heat treated in the horizontal tube furnace. The parameters used in the heat treatment operation were different for each sample, and these

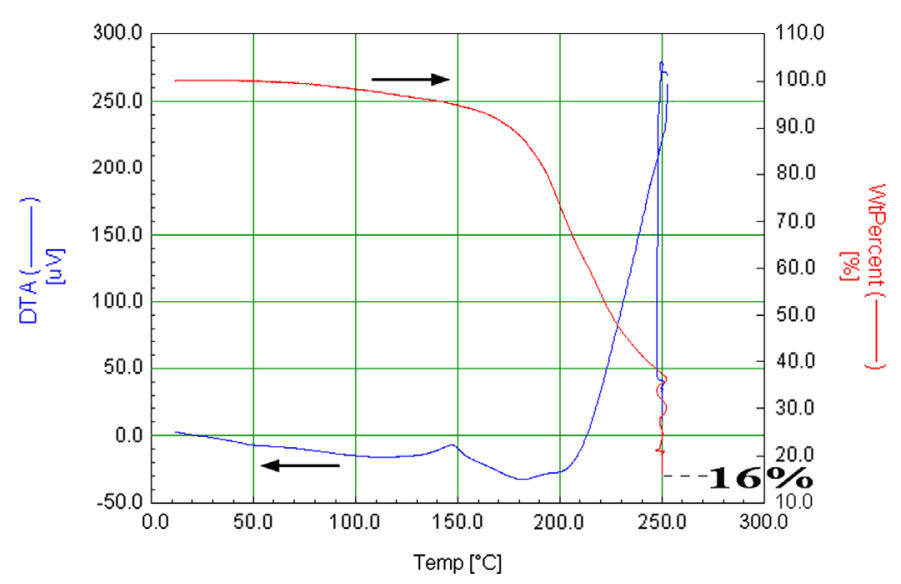

Fig. 5. DTA/TGA curves of sample (G). parameters were the same as those designated as A, G, H and L in Table 1. The results are shown in Fig. 6. One can observe that the spectra of samples A and G are identical demonstrating the presence of the same chemical bonds and molecular structure in both samples. These spectra are clearly different from the spectra of samples $\mathrm{H}$ and $\mathrm{L}$, which are identical on their own, demonstrating the presence of different material (organic residues) beside the cobalt ferrite in both samples.

\subsection{Morphology and particle size}

As stated above, the particle size of ferrite powders is crucially dependent on the temperature during the heat treatment [16,17]. The observed increase in the size at higher temperatures could be a result of the formation of crystalline clusters, clusters of crystals which have become cemented together. However, normally when particles come into contact with each other and under favorable energetic conditions, some of them grow, while others decrease in size and disappear altogether, and so the result is usually a smaller number of larger particles [18].

An FE-SEM image of particles made during the heat treatment carried out using the parameters indicated by $G$ is shown in Fig. 7. This image has been used to estimate the particle size distribution. The sample is composed of nanoparticles in the size range between 7 and $28 \mathrm{~nm}$. The particles are smaller than those in the corresponding FE-SEM image, after the heat treatment parameters indicated by $\mathrm{A}$ were followed (sample 14 in the previous study) [14]. It is evident that the increase in particle size resulted because the heat treatment temperature was allowed to reach a much higher value, $600{ }^{\circ} \mathrm{C}$, in comparison with the temperature indicated by $\mathrm{G}, 250{ }^{\circ} \mathrm{C}$. A histogram of the particle size distribution of sample $\mathrm{G}$ is shown in Fig. 8. As can be seen, the sizes of about $70 \%$ of the particles (The percentage refers to the total number of particles) are smaller than $15 \mathrm{~nm}$. The asymmetric shape of the histogram may indicate that some agglomeration had taken place, with the formation of particles with larger sizes, e.g. around $25 \mathrm{~nm}$.

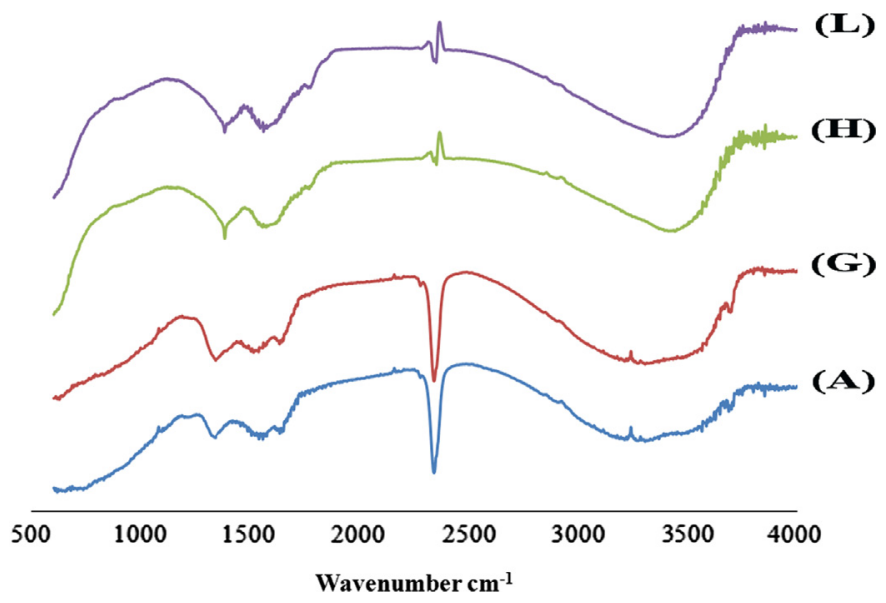

Fig. 6. FTIR spectra of samples (A, G, H, L). 


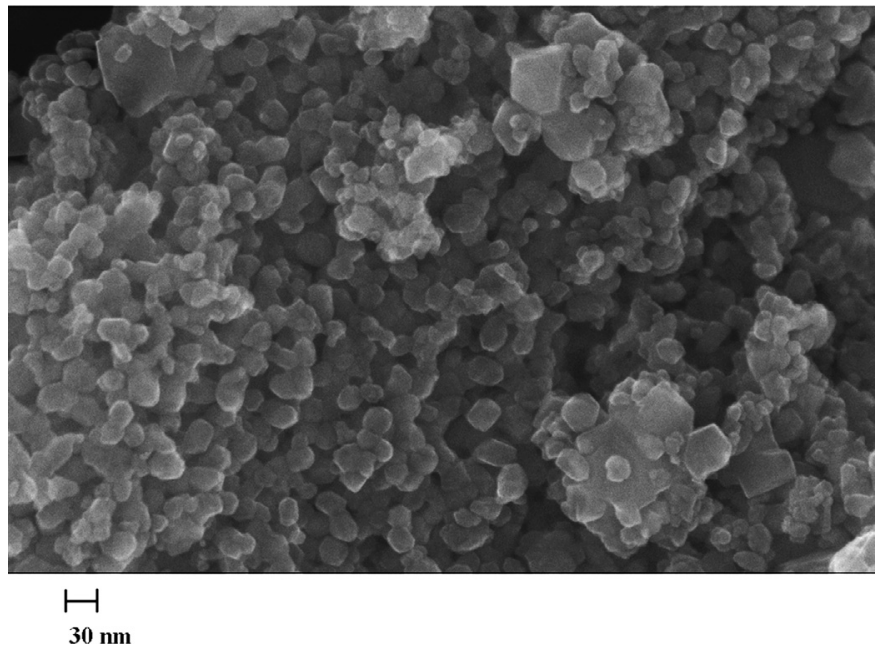

Fig. 7. FE-SEM image of sample (G).

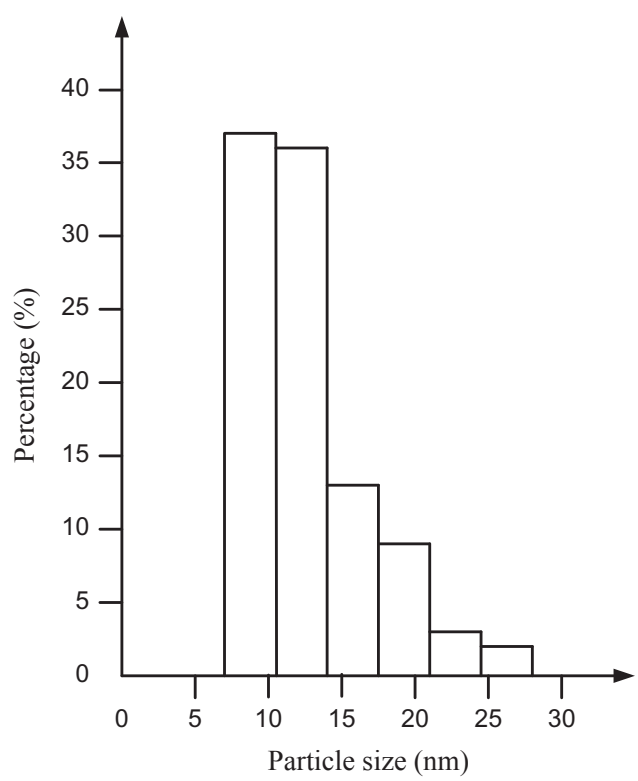

Fig. 8. Particle size histogram of sample (G).

\subsection{Magnetic properties}

The magnetic properties of the nanoparticles in sample $\mathrm{G}$ were investigated in order to determine their magnetic state and to predict their behavior in various circumstances. The hysteresis loop at room temperature is shown in Fig. 9. The saturation magnetization, the remnant magnetization and the coercivity are found to be as follows $62 \mathrm{emu} / \mathrm{g}, 22.5 \mathrm{emu} / \mathrm{g}$ and 1250 Oersteds, respectively (The magnetization indicated in the figure refers to "mass magnetization"). These results are in good agreement with one reference [19] but in obvious disagreement with another reference [20]. In this last reference the saturation magnetization of particles with a size of $25 \mathrm{~nm}$ was estimated to be only $19 \mathrm{emu} / \mathrm{g}$. However, it should be noted that in this case no heat treatment was carried out at the end of the synthesis process. This omission could have had the effect that the particles might have been only partially crystalline and, in turn, this factor may have contributed to a

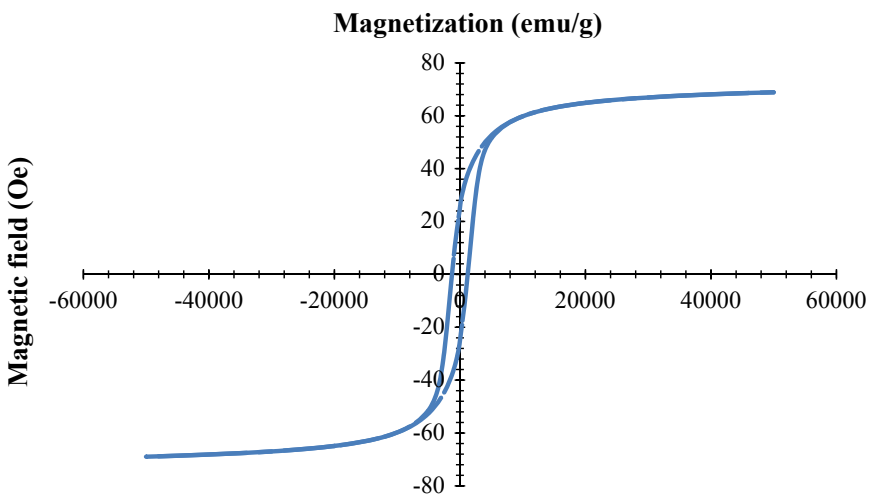

Fig. 9. Hysteresis loop of sample (G) at $300 \mathrm{~K}$.

reduction of the effective size of the particles. Particle size has an important role in decreasing the saturation magnetization and therefore the omission of the heat treatment casts some doubt on the very low value for the saturation magnetization quoted in this reference. The low result for saturation magnetization might be as well due to the presence of organic materials in the sample. If organics were present in large quantities, the magnetic properties would be poor when compared with pure cobalt ferrite, and therefore the magnetic saturation would be smaller. Furthermore, another reference can be quoted which gives support to the above conclusions is as follows: measurements on particles with a size of about $36 \mathrm{~nm}$ provide an estimate for a saturation magnetization of $64 \mathrm{emu} / \mathrm{g}$ [21].

It is now necessary to investigate the magnetic properties at low temperature. Fig. 10 shows the hysteresis loop at $10^{\circ} \mathrm{K}$. The saturation magnetization, the remnant magnetization and the coercivity are $67.3 \mathrm{emu} / \mathrm{g}, 52.5 \mathrm{emu} / \mathrm{g}$ and 10,000 Oersteds, respectively. The coercivity is therefore much greater at the low temperature. This result is in approximate agreement with the results of an investigation [22], in which the magnetic properties of particles with $15 \mathrm{~nm}$ as the average size were studied using a maximum applied magnetic field of $12 \mathrm{kOe}$. The coercivity was estimated from measurements of the hysteresis loops recorded both at room temperature and at $77^{\circ} \mathrm{K}$. The value at $77^{\circ} \mathrm{K}$ was higher than that at room temperature.

The remnant magnetization, $\mathrm{Mr}$, is defined as the magnetization left in a sample after removing the applied magnetic field. Similarly, the coercivity, Hc, is defined as the applied magnetic field necessary to bring the magnetization of a sample to zero. As a comparison between the two loops, Figs. 9 and 10, recorded at $300 \mathrm{~K}$ and at $10 \mathrm{~K}$, reveals, some magnetic properties $(\mathrm{Mr}, \mathrm{Hc})$ are found to have higher values at the lower temperature. This could be understood to be a result of energy barriers in nanoparticles becoming more apparent at lower temperatures. It is suggested that these barriers always exist, but they become more obvious at low temperatures, and they are barriers which retard magnetic moments from aligning towards the applied magnetic field. In this case, more time is required for the magnetic moments to relax resulting in higher values of $\mathrm{Mr}$ and $\mathrm{Hc}$. Their existence may also become more noticeable because a stronger applied magnetic field is required to align the magnetic moments in nanoparticles. 


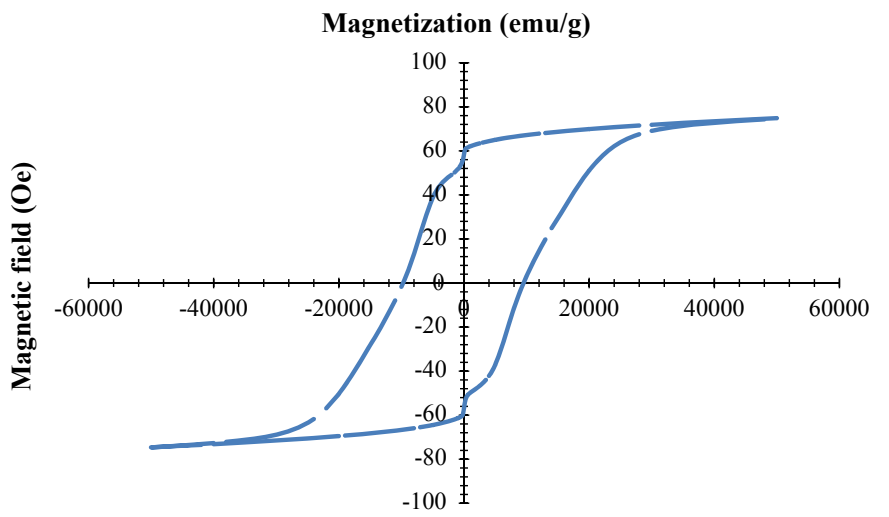

Fig. 10. Hysteresis loop of sample (G) at $10 \mathrm{~K}$.

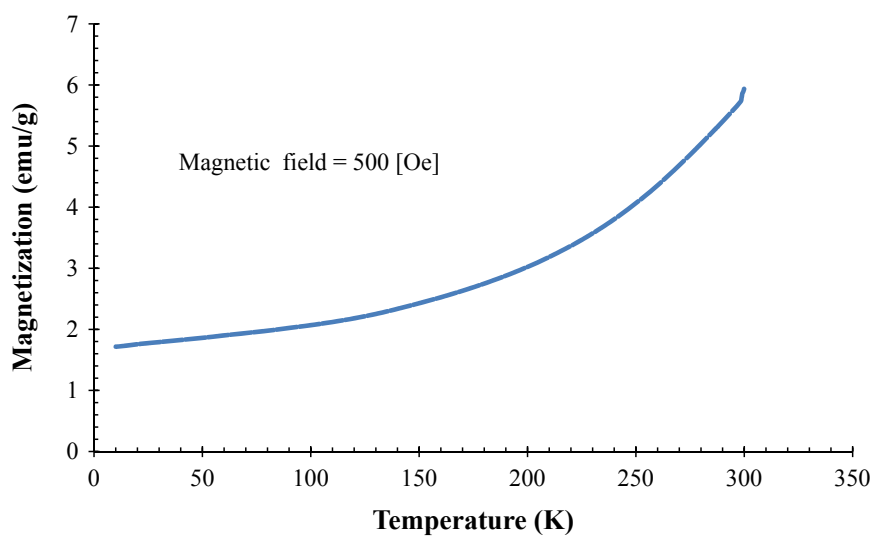

Fig. 11. Temperature dependence of magnetization in ZFC of sample (G).

The temperature dependence of magnetization under zero-field cooled (ZFC) conditions for sample $\mathrm{G}$ is shown as a curve in Fig. 11. The Figure shows that magnetization increases with temperature. For each measurement the magnetization was determined at the same applied magnetic field strength of 500 Oersteds. This magnetic field must have been switched off while the sample was cooled through the transition temperature and then switched on again once a low temperature had been achieved. In other investigations, while the sample is in the ferrimagnetic state, the magnetization increases with temperature, then it reaches a maximum value at the transition temperature between the ferrimagnetic state and the superparamagnetic state, and then it decreases as the temperature continues to rise. The curve in Fig.11 therefore seems to indicate that the majority of particles in sample $\mathrm{G}$ are still in the ferrimagnetic state at $300 \mathrm{~K}$ or room temperature.

\section{Conclusion}

Variations of the parameters of the heat treatment operation, the final stage in the preparation of cobalt ferrite nanoparticles were investigated. The spinel structure was formed in all the products, but in some cases other phases were also present. The impurities in the products were identified. The lowest temperature and shortest dwell time required to prepare cobalt ferrite nanoparticles with a single phase were determined, using techniques involving DTA/TGA equipment and FTIR spectra. The heat treatment parameters of $250{ }^{\circ} \mathrm{C}$ and $10 \mathrm{~h}$, which were the set points chosen for the production of sample $\mathrm{G}$, were selected because they ensured the complete elimination of impurities in the product, while also providing the smallest opportunity for the particles to grow to larger sizes. An FE-SEM image of sample $G$ demonstrated that it was composed of nanoparticles in the size range between 7 and $28 \mathrm{~nm}$. Relevant magnetic properties demonstrated the ferrimagnetic behavior at room temperature of sample $G$ with a saturation mass magnetization of $62 \mathrm{emu} / \mathrm{g}$. With heat treatment parameters as low as $250{ }^{\circ} \mathrm{C}$ and $10 \mathrm{~h}$, the method of preparation described in this study is a significant improvement over the methods reported by other investigators in the state of the art literature.

\section{References}

[1] Z. Chen, L. Gao, Synthesis and magnetic properties of $\mathrm{CoFe}_{2} \mathrm{O}_{4}$ nanoparticles by using PEG as surfactant additive, Materials Science and Engineering: B 141 (2007) 82-86.

[2] A. Grunwald, A.G. Olabi, Design of a magnetostrictive (MS) actuator, Sensors and Actuators A: Physical 144 (2008) 161-175.

[3] M. Shinkai, Functional magnetic particles for medical application, Journal of Bioscience and Bioengineering 94 (2002) 606-613.

[4] N.B. Ekreem, A.G. Olabi, T. Prescott, A. Rafferty, M.S.J. Hashmi, An overview of magnetostriction, its use and methods to measure these properties, Journal of Materials Processing Technology 191 (2007) 96-101.

[5] G. Baldi, D. Bonacchi, M.C. Franchini, D. Gentili, G. Lorenzi, A. Ricci, C. Ravagli, Synthesis and coating of cobalt ferrite nanoparticles: a first step toward the obtainment of new magnetic nanocarriers, Langmuir 23 (2007) 4026-4028.

[6] M. Pita, J.M. Abad, C. Vaz-Dominguez, C. Briones, E. Mateo-Martí, J. A. Martín-Gago, M.P. Morales, V.M. Fernández, Synthesis of cobalt ferrite core/metallic shell nanoparticles for the development of a specific PNA/DNA biosensor, Journal of Colloid and Interface Science 321 (2008) 484-492.

[7] J. Ma, J. Zhao, W. Li, S. Zhang, Z. Tian, S. Basov, Preparation of cobalt ferrite nanoparticles via a novel solvothermal approach using divalent iron salt as precursors, Materials Research Bulletin 48 (2013) 214-217.

[8] S. Li, L. Liu, V.T. John, C.J. O'Connor, V.G. Harris, Cobalt-ferrite nanoparticles: correlations between synthesis procedures, structural characteristics and magnetic properties, IEEE Transactions on Magnetics 37 (2001) 2350-2352.

[9] L. Ajroudi, S. Villain, V. Madigou, N. Mliki, C. Leroux, Synthesis and microstructure of cobalt ferrite nanoparticles, Journal of Crystal Growth 312 (2010) 2465-2471.

[10] N. Millot, S.L. Gallet, D. Aymes, F. Bernard, Y. Grin, Spark plasma sintering of cobalt ferrite nanopowders prepared by coprecipitation and hydrothermal synthesis, Journal of the European Ceramic Society 27 (2007) 921-926.

[11] M. Srivastava, A.K. Ojha, S. Chaubey, P.K. Sharma, A.C. Pandey, Influence of $\mathrm{pH}$ on structural morphology and magnetic properties of ordered phase cobalt doped lithium ferrites nanoparticles synthesized by sol-gel method, Materials Science and Engineering: B 175 (2010) 14-21.

[12] C.J. Brinker, G.W. Scherer, Sol-Gel Science: The Physics and Chemistry of Sol-Gel Processing, Academic Press, San Diego, 1990.

[13] R. Corriu, N.T. Anh, Molecular Chemistry of Sol-Gel Derived Nanomaterials, John Wiley \& Sons, UK, 2009.

[14] M. Sajjia, M. Oubaha, T. Prescott, A.G. Olabi, Development of cobalt ferrite powder preparation employing the sol-gel technique and its structural characterization, Journal of Alloys and Compounds 506 (2010) 400-406. 
[15] M. Sajjia, K.Y. Benyounis, A.G. Olabi, The simulation and optimization of heat treatment of cobalt ferrite nanoparticles prepared by the sol-gel technique, Powder Technology 222 (2012) 143-151.

[16] S.H. Xiao, W.F. Jiang, L.Y. Li, X.J. Li, Low-temperature auto-combustion synthesis and magnetic properties of cobalt ferrite nanopowder, Materials Chemistry and Physics 106 (2007) 82-87.

[17] J.B. Silva, W. de Brito, N.D.S. Mohallem, Influence of heat treatment on cobalt ferrite ceramic powders, Materials Science and Engineering: B 112 (2004) 182-187.

[18] C. Caizer, M. Stefanescu, Magnetic characterization of nanocrystalline $\mathrm{Ni}-\mathrm{Zn}$ ferrite powder prepared by the glyoxylate precursor method, Journal of Physics D: Applied Physics 35 (2002) 3035-3040.

[19] Z. Zi, Y. Sun, X. Zhu, Z. Yang, J. Dai, W. Song, Synthesis and magnetic properties of $\mathrm{CoFe}_{2} \mathrm{O}_{4}$ ferrite nanoparticles, Journal of Magnetism and Magnetic Materials 321 (2009) 1251-1255.
[20] J. Wang, T. Deng, Y. Lin, C. Yang, W. Zhan, Synthesis and characterization of $\mathrm{CoFe}_{2} \mathrm{O}_{4}$ magnetic particles prepared by co-precipitation method: effect of mixture procedures of initial solution, Journal of Alloys and Compounds 450 (2008) 532-539.

[21] C.N. Chinnasamy, M. Senoue, B. Jeyadevan, O. Perales-Perez, K. Shinoda, K. Tohji, Synthesis of size-controlled cobalt ferrite particles with high coercivity and squareness ratio, Journal of Colloid and Interface 263 (2003) 80-83Sci 263 (2003) 80-83.

[22] B.G. Toksha, S.E. Shirsath, S.M. Patange, K.M. Jadhav, Structural investigations and magnetic properties of cobalt ferrite nanoparticles prepared by sol-gel auto combustion method, Solid State Communications 147 (2008) 479-483. 